\title{
Estética do consumo: uma perspectiva a partir da ecologia publicitária
}

\author{
CLOTILDE PEREZ \\ VICTOR AQUINO
}

\section{Resumo}

O presente texto é resultado da reflexão teórica sobre estética, estética do consumo e ecologia publicitária. Tais resultados reflexivos são decorrentes das pesquisas do $\mathrm{GESC}_{3}$ (Grupo de Estudos Semióticos em Comunicação, Cultura e Consumo) e do CEDE (Coletivo de Estudos de Estética), cujos trabalhos buscam agregar o pensamento crítico multidisciplinar entre o estudo do consumo e a publicidade. Tais estudos são marcados pela forte pesquisa empírica, alicerçada nos métodos semióticos e na etnografia levados a cabo na última década. $\mathrm{O}$ resultado destas reflexões nos leva ao entendimento de que o consumo é hoje essencialmente um consumo estético, quer pelas visualidades e sensorialidades exploradas nas ofertas materiais, quer pelas explorações conceituais de temas emergentes, como gênero, etnia, ageless e tantos outros que também são abordados esteticamente nas campanhas e expressividades das marcárias.

Palavras-chave:

Estética, estética do consumo, gosto, ecologia publicitária 


\title{
Aesthetics of consumption: A perspective from the advertising ecology
}

\section{CLOTILDE PEREZ}

VICTOR AQUINO

\begin{abstract}
This paper results from a theoretical reflection on aesthetics, aesthetics of consumption and aesthetics and advertising. It is a consequence of a research in progress in GESC $_{3}$ (Center of Semiotic Studies in Communication, Culture and Consumption) and in CEDE (Center of Aesthetic Studies), whose works look for joining the multidisciplinary thinking among consumption studies and advertising. These researches are identified by empiricism, founded in semiotic methods and in ethnography in the last decade. All researches show us that nowadays consumption is essentially an aesthetic consumption, perceived by the visual or sensorial aspects in the material offers, or in the conceptual exploitations of gender, ethnicity, age and so many others aesthetically aspects emphasized by advertising campaigns, as well as by the several brands' expressivities.
\end{abstract}

Keywords: 


\section{Estética y consumo: un punto de vista a partir de la ecología publicitaria}

\section{CLOTILDE PEREZ \\ VICTOR AQUINO}

\section{Resumen}

Este texto es resultado de la reflexión teórica sobre estética, estética del consumo y ecología publicitaria. Esos resultados reflexivos derivan de las investigaciones del GESC 3 (Grupo de Estudios Semióticos en Comunicación, Cultura y Consumo) y del CEDE (Colectivo de Estudios de Estética), cuyos trabajos buscan agregar el pensamiento crítico multidisciplinario al estudio del consumo y la publicidad. Esos estudios están marcados por la fuerte investigación empírica, basada en los métodos semiotico y en la etnografía, desarrollados en la última década. El resultado de estas reflexiones nos lleva al entendimiento de que el consumo es hoy esencialmente consumo estético, tanto por las visualidades y sensorialidades explotadas en las ofertas materiales, como en las exploraciones conceptuales de temas emergentes como género, etnia, ageless y tantos otros, que también son tratados estéticamente en las campañas y expresiones marcadas.

Palabras clave:

Estética, estética del consumo, gusto, ecología publicitaria 


\section{A Estética e as conexões de sentido com o gosto}

Uma ideia inicial sobre estética, antes de qualquer coisa, leva a indagar: como esse conceito, por vezes tão difuso quanto complexo, adquiriu tamanha importância na contemporaneidade? A resposta envolve duas dimensões de sentidos amplos. Primeiro, uma dimensão filosófica que, tratando o significado do ponto de vista subjetivo, considera o termo aplicável ao que se classifica segundo o gosto. Segundo uma dimensão prática, que relaciona o termo a significados muitas vezes diferentes, a uma série de eventos. Esses eventos vão de gêneros de linguagem a práticas humanas, passando inclusive pelos erros, ou equívocos, das interpretações conceituais correspondentes.

Como se sabe, a origem da palavra estética data de 1735. Trata-se de um neologismo criado por Alexander Gottlieb Baumgarten (1954), à época um professor quase desconhecido da Brandenburgische Universität Frankfurt. Na primeira vez que usou o termo, ao publicar o pequeno trabalho Meditações filosóficas sobre as questões da obra poética, quase ninguém o levou a sério. Neste, como em outra publicação, o pequeno opúsculo mais conhecido de sua autoria, Estética, deixado inacabado (pois Baumgarten morreria precocemente antes de completar 48 anos), o autor justificava a necessidade de encontrar um termo que explicasse, com precisão, a natureza das sensações produzidas por qualquer obra cuja percepção "impactasse" qualquer pessoa.

Bom ressaltar, na origem da criação do neologismo e do interesse por estudos que, de algum modo, perseguiam as ideias de Platão, Sócrates e Aristóteles, depois continuados, entre outros, por Plotino e Santo Agostinho, a preocupa- 
ção era o esclarecimento dos significados de "belo", "bom" e "bonito", principalmente na arte. Significados que, com o passar do tempo, foram migrando para outras situações e eventos. Entre os séculos XVI e XVIII, por exemplo, esse foi um assunto que ocupou uma infinidade de grandes nomes da filosofia, como Bacon, Hobbes, Locke, Berckeley, Hume e Leibniz. Contemporâneo de Baumgarten, Emmanuel Kant terá sido o responsável por se apropriar (sem nunca ter se referido à origem) do termo, tornando-o conhecido no meio acadêmico. O criador do termo estava muito preocupado com a necessidade de classificar o sentido de "belo" quando não era apenas isso que importava, mas sim a sensação que qualquer coisa, fosse bela ou não, provocava ao ser percebida. Desde as primeiras discussões e durante muito tempo, estética tanto representou o entendimento de algo que se estabelecia como área de filosofia da arte, quanto os significados que o termo passaria a agregar.

Todavia, um complicador do respectivo entendimento contribuiria para ampliar a definição do termo a partir daí. Em primeiro lugar, talvez tenha sido em função de atordoante exigência de adaptação dos estudos de estética, levando os estudiosos do assunto à redefinição e readaptação de seu significado por causa das transformações ocorridas na arte na passagem do século XIX para o século XX. Isto porque a natureza da observação, do impacto e das sensações decorrentes da percepção de qualquer obra de arte começava a distinguir-se e já não seria a mesma, nem poderia equivaler ao que ocorria desde o Renascimento. Em segundo lugar, por causa de um aparente uso do termo estética como sinônimo de beleza, do qual ocorreriam outras utilizações.

Em um colóquio realizado no escritório do arquiteto Oscar Niemeyer, em 1999, o cirurgião plástico Ivo Pitanguy relatou uma passagem que talvez explique a apropriação do termo pela medicina. Esse relato está transcrito em Aesthetics as way for watching Art and things (AQUINO, 2002). Em um congresso de cirurgia plástica, do qual participou em Genebra, nos anos de 1950, o cirurgião referiu-se pela primeira vez a essa especialidade médica, como medicina estética. A referência, por parentesco com o significado de beleza, ou de embelezamento, "contaminaria" o sentido filosófico do termo, ensejando a partir de então sua indiscriminada utilização. Hoje é comum perceber seu uso em cosmetologia, salões de cabeleireiro, maquiagem, bronzeamento e em uma infinidade de outras situações, como na gastronomia. 
Em meio a essa variedade de significações, já em meados do século $\mathrm{XX}$, incontáveis pesquisadores dedicavam-se a buscar, principalmente no terreno da filosofia, a precisão conceitual de alcance acadêmico. Um dos principais nomes que emergiriam nesse contexto foi o do professor francês Raymond Bayer (1898-1959). Entre a densa e profícua obra, dedicada sobretudo a rever as ideias de Kant, elaborar um método de pesquisa estética e, ainda, um longo tratado de estética, destaca-se um não menos denso e longo livro sobre o que ele denominou de História da estética (BAYER, 1961).

Se por um lado a incorporação de outras circunstâncias, como de objetos e eventos além da arte, terá contribuído para tornar mais complexo o entendimento do sentido de estética, por outro, embora até certo ponto complicando o seu estudo, essa complexidade também contribuiu para que se enriquecessem as reflexões a seu respeito. Tudo, claro, muito além daquilo que anteriormente se entendia apenas por beleza. Pois tem a ver, principalmente, com gosto, com a tendência de gosto, com a abrangência de gosto e, sobretudo, com tudo que se relaciona ao gosto.

Em trabalhos mais atuais sobre estética, compreende-se a razão pela qual a nova dimensão do significado de estética foi até mesmo incorporada aos estudos de arte. Goldblatt (2016), por exemplo, sugere que não há um padrão definitivo, ou pré-estabelecido, para a forma ou conteúdo da obra de arte. A classificação, o gosto, a aceitação, ou não, dependem sempre de quem percebe, observa, apropria-se dela ou a retém.

Em uma dessas publicações, até certo ponto de singular exagero, apesar de extremamente aplicável ao modo como os seres humanos definem suas preferências estéticas, Prum (2017) recorre a uma comparação entre as espécies do mundo animal, citando Darwin, para justificar que o gosto nem sempre está associado a uma questão cultural. Aliás, se cabe um comentário, a obra em questão pode até não se converter em uma referência apropriada para o campo da estética, em si, no entanto, o exemplo a partir do qual o autor esboça uma comparação entre o mundo animal e os seres humanos serve para justificar as razões pelas quais cultura, unicamente, não chega a ser um fator determinante do gosto. Se isto fosse determinante, por exemplo, a globalização dos mercados, que começou a aportar campanhas de publicidade internacionalizadas, teria pasteurizado o gosto. Há, claro, situações de preferências de gosto determinadas pelas culturas locais, que também estabelecem modos de perceber e apreciar qual- 
quer coisa. Mas há igualmente situações em que se apreciam coisas novas, não comuns, que aportam sobre culturas locais como novidades, antes desconhecidas, cuja apreciação é determinante na formação do gosto, ou de uma nova tendência de gosto.

Há pesquisadores que, embora ainda insistindo sobre essa questão de diferenças, virtualmente existentes em períodos do regime comunista - mas até nisso a comparação pode não ser precisa -, descrevem um modelo de formulação de gosto com base na estrutura econômica. $\mathrm{O}$ que não chega a ser errado, mas também não é de todo correto, pois o desejo de posse, um dos determinantes do consumo, independe tanto da condição financeira, como da disponibilidade de oferta, ou igualmente daquilo que se orienta a consumir.

Esse é o caso de uma obra publicada em 1986 (HAUG, 1986), que considerava criticamente a oferta indiscriminada de bens de consumo, própria das sociedades capitalistas, sem levar em conta que o desejo de posse influenciado pelo gosto mesmo no âmbito das sociedades capitalistas - nem sempre é resultado apenas da oferta indiscriminada desses bens. Caso, por exemplo, de um automóvel Rolls Royce, que poderá ser querido infinitamente por alguém que não o possa adquirir.

Mas, não só. A formulação do gosto - respaldado em uma vertente marcadamente estética, que pressiona pelo desejo de possuir uma joia, e sempre associado àquilo que se convencionaria como "glamour" (ou seja, uma posse movida apenas por uma distinção do possuidor), como quer Postrel (2013) - estabelece que o gosto de uma pessoa é determinado não apenas por uma variável de distinção pessoal, como também pela evidência de gosto de outras pessoas. E isto pode ocorrer do campo das artes ao do consumo de bens. Justamente por esta razão deve-se levar em conta que estética é condição indissociável do processo de consumo, qualquer que seja ele.

Aceitando-se, então, que estética é indissociável do consumo é aceitar também que ela é indissociável da publicidade. Aliás, em outro trabalho já bastante antigo, publicado em 1988, Wicker considerava que se pode realizar como que uma interpretação das culturas a partir do que a autora denominou de "fundamentos das formas estéticas" que transcenderiam a publicidade.

Sem sombra de dúvida, esta é a principal justificação do estudo de estética em publicidade. Pois, em outras palavras, estética é o que nivela o gosto, fazendo com que se goste ou se aprecie, ou que se rejeite alguma coisa que se está vendo, 
lendo, ouvindo, assistindo, ou que existe na perspectiva de um evento percebido por um grande conjunto de pessoas.

Como tudo o que há no mundo, entretanto, a condição estética é objeto de múltiplas interpretações. Seja quando se gosta de alguma coisa só porque aquilo não está sendo apreciado por uma maioria expressiva de pessoas, fato que pode resultar, digamos, em uma "aberração do gosto". Isto é, quando se gosta de algo fora de um "padrão" ou de algo rejeitado pela maioria. Quase sempre esse evento é reduzido por essa maioria como "mau gosto". Quase sempre esse evento é reduzido por essa maioria como "mau gosto". Caso típico, por exemplo, da manifestação de preferência por músicas consideradas bregas, roupas em desuso, literaturas "proscritas" ou de autores "proscritos" e assim por diante.

Em publicidade não há espaço para indefinição de gosto. Tudo que se cria, se produz e se veicula, sendo assistido por uma audiência de proporções muitas vezes incalculáveis, deve ser aceito e apreciado sem objeção (ou que tenha a mínima rejeição). O segredo da boa publicidade, assim, está nessa aceitação, independente do fato de quem aceite, ou goste daquilo que está sendo exibido, ser levado à aquisição posteriormente.

Este não é o espaço para, necessariamente, conceituar publicidade. Entretanto, para que se entenda com precisão a função da estética em publicidade, torna-se importante resumir que publicidade é um instrumento do marketing. Assim mesmo, embora constando do respectivo projeto, é autônomo com relação ao marketing. No correspondente processo de criação, produção e veiculação, cumprindo as metas que este lhe atribui, desenvolve-se com autonomia criativa no desenvolvimento das peças de uma campanha requerida, que posteriormente faz veicular nas mídias eleitas e fora delas.

Desse modo, pode-se dizer que a publicidade é o processo mediante o qual se expressa, com ingredientes estéticos, o que o projeto de marketing pretende dizer em uma determinada campanha. Ao contrário do que postula uma série de seminários, ao discutir um conceito acadêmico de "anti-estética" criado por Hall Foster (2002), constante de publicação em 2001, em uma série de livros sobre a questão (ELKINS, 2015), estética em publicidade não abdica de uma aprovação de gosto.

Aliás, essa discussão serve, antes de mais nada, para evidenciar uma distinção do estudo de estética entre as artes e a publicidade. Em publicidade, o gosto comum, identificador 
de uma estética corrente, carece sobretudo de identificação, objetividade e aceitação. Porque isto é a chave para a aceitação do que se exibe em uma campanha independente da mídia. Tudo mais, como variações de gosto, aberração de gosto, ou rejeição, é altamente comprometedor do sucesso que se espera ter.

\section{A estética do consumo na contemporaneidade}

Com a sociedade e o pensamento complexos (MOURIN; LE MOIGNE, 2000) e todas as reflexões e constatações da vida na sociedade pós-moderna, envolvendo as distintas perspectivas filosóficas, antropológicas, políticas, tecnológicas... (LIPOVETSKY, 2007; LIPOVETSKY; SERROY, 2015; HALL, 2002; GIDDENS, 1991, 2002; BAUMAN, 2008; JENKINS, 2009; SLOTERDIJK, 2004), é impossível pensar em caminhos para o encontro entre pessoas e marcas, e do consumo como um todo, que se apresentem de forma simples. Como vimos em reflexões anteriores (TRINDADE, 2005; TRINDADE; PEREZ, 2014 e PEREZ, 2004, 2016), há inquietação na universidade, responsável pelo pensamento e o avanço das ciências, constatada pela criação de vários conceitos, como: publicização, sistema publicitário, ecossistema publicitário (PEREZ, 2016), hiperpublicidade, publicidade híbrida, ciberpublicidade, promocionalidade e outros. Mas também há grandes movimentações no mercado, que se encontra na lógica da pressão do tempo e dos resultados, em uma prática desenfreada de inovação, muitas vezes sem fundamentos consistentes e até inconsequentes, como tem sido frequente na expressão da inabilidade em lidar com questões tensionadas, como gênero, idade, perspectivas morais diversas.

Toda esta complexidade é necessária diante da certeza de que estamos vivendo a hipertrofia das mercadorias a favor da expansão dos signos sensíveis e das experiências estéticas. E a publicidade tem que dar respostas a isso, quando não, deve ser fenômeno construtor, fomentando estes caminhos, cumprindo sua função ativa como edificadora de valores sociais. $\mathrm{O}$ mundo está sendo remodelado pela lógica da mercantilização e da individualização extremas (permitida pelo big data e pelos algoritmos), constituindo um certo capitalismo artístico ou mais precisamente uma "transestética", na visão de Lipovetsky e Serroy (2015). Os autores afirmam que estamos presenciando e vivendo "uma espécie de hiperarte que se infiltra nos interstícios da vida cotidiana [...]", a esté- 
tica está em tudo e agora com a força da massificação digital-presencial. E a ecologia publicitária, como veremos adiante, é a ambiência integradora dessas manifestações sensíveis.

$\mathrm{Na}$ contemporaneidade, o consumo deixa de ter ênfase nas relações de compra, ainda que nos estudos de marketing essa perspectiva seja predominante, passando a uma visão de processo. Esse momento de crescimento e saída do reducionismo que a "compra" implicava só foi possível pela incorporação do consumo como área de estudo no âmbito das comunicações e da semiótica, a qual, já na origem, percorreu o diálogo com a antropologia (antropologia do consumo, antropossemiótica...), com a psicanálise (estudo sobre o desejo e as manifestações do inconsciente), com o design, no sentido amplo, e, mais recentemente, com as tecnologias digitais (redes sociais, influenciadores, algoritmos etc.).

O entendimento do consumo em uma perspectiva antropossemiótica encontra ressonância nos estudos acerca dos rituais de consumo, que foram rentabilizados a partir das pesquisas de McCracken (2003), mas também com as reflexões precursoras na Antropologia sobre os rituais (TURNER, 2013; VAN GENEPP, 2008 e outros) e as pesquisas do GESC 3 - Grupo de Estudos Semióticos em Comunicação, Cultura e Consumo (TRINDADE; PEREZ, 2014). Os rituais de consumo, ressignificados de acordo com o segmento da cultura material estudada, pressupõem, genericamente, o entendimento acerca da busca, da compra, da posse, do uso e do descarte ou ressignificação. Este entendimento amplo e ritualístico permite penetrar na complexidade das relações de consumo, ampliando as reflexões acerca da racionalidade do consumo em direção ao entendimento dos fundamentos emocionais e, portanto, sensíveis e estéticos que movem o consumo, tanto nos processos de escolha, quanto de uso cotidiano, de guarda, de descarte ou não, como acontece no caso das ressignificações, em que produtos e embalagens assumem novas funções práticas e emocionais, por vezes muito distantes de sua funcionalidade de origem, como embalagens de bebida que se transformam em abajur.

Tanto as reflexões teóricas engendradas na articulação da comunicação, da semiótica, da antropologia, da psicanálise e do design, quanto a empiria levada a campo em vários projetos de pesquisa ao longo da última década nos levam à conclusão de que o consumo contemporâneo é consumo estético na essência. Ou seja, que tanto a dimensão estética expressa nas visualidades de produtos e serviços, 
vitrinas, identidades visuais, lojas, páginas da web, blogs, aplicativos, publicidades em geral, quanto outras dimensões sensíveis - como fragrâncias, gestualidades, signos sonoros, texturas e sabores - determinam o consumo em todos os rituais. Apenas como exemplo, por meio de um dos projetos de pesquisa em sua fase de campo, foi possível constatar o estiramento da fase final do consumo (descarte) simplesmente porque os consumidores tinham forte relação afetiva com as embalagens, sintetizada na frase "são lindas". No caso, eram mulheres brasileiras, classe $\mathrm{AB}$, que acumulavam frascos de perfume e de potes de cremes para o rosto, todos vazios. Ou seja, a materialidade das embalagens (vidros e acrílicos refinados), bem como o design dos frascos, as cores e também as marcas (rotulagem e toda a subjetividade embarcada) eram os gatilhos de sentido para os vínculos emocionais, o que em última instância as impedia de descartar esses objetos.

\section{Ecologia publicitária: promoção e construção da estética do consumo}

Como um fenômeno característico da civilização moderna, a publicidade constrói e reflete a sociedade (PEREZ, 2004, p. 105; 2011, p. 61; TRINDADE, 2005, p. 87). Há mais de uma década esta afirmação indiciava a compreensão da publicidade não apenas como espelho da sociedade, como seu duplo, no sentido de reforço da realidade social, mas na sua capacidade edificadora desta mesma sociedade. Em esforço teórico subsequente, materializado nos livros Hiperpublicidade 1 e Hiperpublicidade 2 (PEREZ; BARBOSA, 2007), os autores apresentaram as reflexões que avançavam no sentido de identificar o crescimento da publicidade (aqui expresso já no título com o prefixo "hiper" em conexão com os tempos hipermodernos de Lipovetsky e Charles [2004]). E este crescimento estava relacionado em parte ao trânsito dos objetos publicitários: desde a afirmação "mais que anunciar produtos, significar marcas" (PEREZ, 2004, p. 111), a movimentação e o esforço de construir universos de sentido das/ para as marcas era evidente. Causa e consequência da sociedade alicerçada no conhecimento e nos serviços, as marcas assumiram a centralidade no consumo, instaurando um novo fundamento: a comunicação da imaterialidade, o valor da subjetividade, o crescimento simbólico e o entendimento dos valores sociais como caminho consequente para a construção de posicionamentos mercadológicos vigorosos. Já havia aqui 
a constatação do transbordamento: "As marcas acabam por se desencarnar dos produtos que lhe deram origem passando a significar algo muito além deles próprios" (PEREZ, 2004, p. 111), o que também pode ser evidenciado na visão de Lipovetsky sobre a publicidade atual:

A publicidade passou de uma comunicação construída em torno do produto e de seus benefícios funcionais a campanhas que difundem valores e uma visão que enfatiza o espetacular, a emoção, o sentido não literal, de todo modo significantes que ultrapassam a realidade objetiva dos produtos. (LIPOVETSKY, 2007, p. 34).

Outros esforços teóricos são encontrados, sendo que um deles é especialmente interessante, a ideia de uma ecologia publicitária. Nesse sentido, a ecologia publicitária contempla todos os públicos, processos e mídias envolvidos na busca de promover o "encontro profícuo" entre os fluxos de comunicação, as pessoas e a oferta material/marcas. Baseado na ideia de meeting points - pontos de encontro (DI NALLO, 1999), busca lidar com a complexidade e a diversidade das interações comunicacionais instauradas na contemporaneidade: digital, presencial, ênfase na efemeridade, fusão produção-consumo, compartilhamento... Em sentido semelhante, mas trazendo a dinâmica dada pela ação, o conceito de publicização (CASAQUI, 2009) que está baseado na teoria das mediações de Martín-Barbero (2001) define-se como processo publicitário e deve ser compreendido em seu contexto mais amplo: como mediador das relações entre produção e consumo, ou seja, como linguagem que torna possível a realização plena das duas esferas, uma vez que, como defende Marx (1974), a produção somente se realiza no consumo, e o consumo só se efetiva a partir daquilo que é ofertado ao consumo pela esfera produtiva.

O discurso publicitário é a voz que representa a estética da mercadoria e lhe atribui traços, características humanas que "lançam olhares amorosos aos consumidores", em consonância com a leitura da obra marxista feita por Haug (1986, p. 39). Expandimos essa compreensão da função da comunicação no sistema produtivo, uma vez que o discurso publicitário é municiador de atributos intangíveis, que dialogam com os interesses, necessidades, desejos, quereres dos indivíduos, abordados como consumidores potenciais pelas mensagens que lhes são direcionadas, objetivando estimular 
sua ação (CASAQUI, 2009, p. 3). Em 2011, Casaqui evolui suas reflexões e afirma:

A velha publicidade se transmuta em publicização e assimila o consumidor em sua trama para propor novos significados para as relações entre produtores e consumidores - muitas vezes, embaralhando os papéis para construir o sentido da legitimidade, da identidade com seu "público-alvo", para, enfim, mergulhar no espírito do seu tempo e emergir como fantasmagoria cada vez mais complexa, mais instigante (CASAQUI, 2011, p. 148).

Assim, chegamos à ecologia publicitária como um constructo teórico integrativo. $\mathrm{O}$ conceito encontra sua origem nas pesquisas empíricas e teóricas da Ecologia, ciência que busca entender as relações mútuas entre os organismos e o mundo exterior, que por sua vez é um ramo da Biologia, a tão conhecida ciência da vida. Ainda que cada vez mais em diálogo interdisciplinar (SANTAELLA, 2010, p. 14), essa filiação constitutiva é indelével.

Nesse sentido, quando aproximamos Ecologia de Publicidade, estamos buscando deliberadamente a ênfase nas relações de consumo, não apenas na compra, mas nos diferentes rituais de consumo. Como afirma Santaella sobre o uso metafórico do conceito Ecologia:

Nada mais natural que os estudos linguísticos e de comunicação se apropriarem do termo, pois o comportamento das línguas e de todos os demais tipos de signo e as dinâmicas comunicacionais que ensejam apresentam fortes similaridades com os organismos vivos (SANTAELLA, 2010, p. 15).

Ecologia publicitária, portanto, refere-se às ações e relações publicitárias que funcionam, e o que isto significa? Se o objetivo máximo da Publicidade é construir vínculos de sentido entre pessoas e marcas (produtos, serviços, ideias, propostas etc.), a questão que se põe ultrapassa qualquer possibilidade de aprisionamento midiático. Ou seja, transborda. As ideias colocadas em prática que busquem esta relação (pessoas-marcas) pertencem a uma ecologia publicitária. Assim, as práticas promocionais, merchandising, insert, product placement, gameficação, blitz, ativação, marketing de relacionamento, branded content, loja conceito, flashmobs, aplicativos etc., bem como suas estruturas e supor- 
tes (internet, TV, rádio, cinema, rua, casa, todas as telas e tudo o mais que surgir) integram esta Ecologia. Não apenas anunciante - agência - veículo, agora temos os mais diferentes parceiros na construção e implementação das soluções: empresas de infraestrutura, de sistemas sofisticados de algoritmos, de monitoramento de redes sociais, de robótica, inteligência artificial, eventos, empresas de conteúdo etc., os próprios consumidores nas suas funções de prosumers ou de consumidores-autores. Além da diversidade de parceiros e instituições que colaboram na criação, há que se considerar as inúmeras possibilidades de formação na sua produção, de publicitários a engenheiros, passando por DJs, fotógrafos, youtubers, antropólogos, semioticistas, filósofos, psicanalistas, programadores...

A ecologia publicitária é um conceito que pretende ser integrador e apaziguador (pelo menos provisoriamente) das tensões, imprecisões e insatisfações com as pesquisas e práticas publicitárias atuais. E seu entendimento pressupõe uma visão ampliada acerca do consumo, compreendendo-o como um ritual, com as complexidades, diferenças e fases, em um contexto movente, com consumidores complexos e também voláteis.

A estética do consumo tem na ecologia publicitária sua condição de existência. Assim, é a publicidade que dá a ver e a sentir as dimensões sensíveis das ofertas materiais e simbólicas, determinando as relações de consumo e a formação do gosto, tanto na perspectiva das materialidades que atendem aos consumidores (materiais, design, formas etc.), quanto dos conceitos engendrados nos posicionamentos marcários contemporâneos, como sustentabilidade, genderless, ambiguidades etc., que também se manifestam esteticamente.

\section{Considerações finais}

Como vimos, muitas são as possibilidades de conceituar estética, no entanto, para os fins que nos interessam neste momento, o caminho nos leva ao entendimento da estética na perspectiva publicitária e de consumo, diferenciando-a das artes e da filosofia. Em publicidade, o gosto ordinário que manifesta uma estética corrente demanda principalmente a identificação com as pessoas, o público-alvo da campanha, portanto, deve apresentar uma perspectiva bem objetiva, uma vez que pretende a aceitação, não necessariamente a compra ou adesão, mas um vínculo positivo a partir do que 
chamamos de identificação. Independente da mídia, a aceitação é incondicional, uma vez que variações de gosto, aberração de gosto, ou rejeição são altamente comprometedoras do sucesso que se espera ter em uma comunicação publicitária.

E a estética cresce como valor no consumo a partir do momento que ocorre o descolamento da comunicação vinculada à objetividade e funcionalidade de produtos e serviços, a favor dos apelos emocionais e subjetivos das marcas. E essas explorações seguem pelos caminhos das manifestações sensíveis das distintas possibilidades visuais, das texturas e gestualidades, fragrâncias, sabores e sonoridades, bem como de suas sobreposições e sinestesias. A viabilizadora dessas possibilidades de contato entre públicos e expressividades marcárias é a ecologia publicitária, ou seja, toda a complexidade de atores, mídias transbordadas, linguagens e mensagens engendradas a favor da construção de vínculos de sentido que se converterão em adesão à marca.

\section{Referências}

AQUINO, Victor. Aesthetics as way for watching Art and things. Monroe: WEA Books, 2002.

BAUMAN, Zygmunt. Vida para o consumo: a transformação das pessoas em mercadoria. Rio de Janeiro: Zahar, 2008.

BAUMGARTEN, A. G. Reflections on poetry: meditationes philosophicae de nonnullis and poema pertinentibus. Berkeley: University of California Press, 1954.

BAYER, Raymond. Histoire de l'esthétique. Paris: Armand Colin, 1961.

CASAQUI, Vander. Por uma teoria da publicização: transformações no processo publicitário. Significação: revista de cultura audiovisual, São Paulo, v. 36, p. 131-151, 2011.

A esfera simbólica da produção: estratégias de publicização do mundo do trabalho na mídia digital. Rumores, São Paulo, v. 6, 2009. Não paginado.

ELKINS, James (Ed.) Beyond the aesthetic and the anti-aesthetic: the stone art theory institutes. University Park, Penn State University Press, 2015.

FOSTER, Hall. The anti-aesthetic: essays on post-modern culture. New York: The New Press, 2002.

GIDDENS, Anthony. As consequências da modernidade. São Paulo: Unesp, 1991. - Modernidade e identidade. Rio de Janeiro: Jorge

Zahar, 2002. 
GOLDBLATT, David. Aesthetics: a reader in philosophy of the arts. 2 ed. Nova York; Abingdon: Routledge, 2016.

HALL, Stuart. A identidade cultural na pós-modernidade. Tradução Tomaz Tadeu da Silva e Guacira Lopes Louro. 7 ed. Rio de Janeiro: DP\&A, 2002.

HAUG, Wolfgang Fritz. Critique of commodity aesthetics: appearance, sexuality, and advertising in capitalist society. Minneapolis: University of Minnesota Press, 1986.

JENKINS, Henry. Cultura da convergência. São Paulo: Aleph, 2009.

LIPOVETSKY, G. O Império do efêmero. São Paulo: Cia das Letras, 2007.

LIPOVETSKY, Gilles; CHARLES, S. Os tempos hipermodernos. São Paulo: Barcarolla, 2004.

LIPOVETSKY, Gilles; SERROY, Jean. A estetização do mundo: viver na era do capitalismo artista. São Paulo: Cia das Letras, 2015.

MARTÍN-BARBERO. J. Dos meios às mediações. Comunicação, cultura e hegemonia. 2. ed. Rio de Janeiro: Editora UFRJ, 2001.

MARX, K. O capital: crítica da economia política. São Paulo: Civilização Brasileira, 1974 .

MCCRACKEN, Grant. Cultura e consumo. Rio de Janeiro: Mauad, 2003.

MORIN, Edgard; LE MOIGNE, JL. A Inteligência da Complexidade. São Paulo: Petrópolis, 2000.

PEREZ, Clotilde. Ecossistema publicitário: o crescimento sígnico da Publicidade. In: INTERCOM, 39., 2016. Anais... São Paulo: Intercom, 2016.

Signos da marca: expressividade e sensorialidade. São Paulo: Cengage Learning, 2004.

POSTREL, Virginia. The power of glamour: longing and the art of visual. New York: Simon \& Schuster, 2013.

PRUM, Richard O. The evolution of beauty: how darwin's forgotten theory of mate choice shapes the animal world and us. New York: Doubleday, 2017.

SANTAELLA, Lucia. A ecologia pluralista da comunicação: conectividade, mobilidade, ubiquidade. São Paulo: Paulus, 2010.

SLOTERDIJK, Peter. Sphären III - Schäume. Frankfurt: Suhrkamp, 2004.

TRINDADE, Eneus. A publicidade e a modernidade-mundo: as representações de pessoas, espaço e tempo. In: BARBOSA, I. (Org.). Os sentidos da publicidade. São Paulo: 
Thomson Learning, 2005.

TRINDADE, Eneus; PEREZ, Clotilde. Os rituais de consumo como dispositivos midiáticos para a construção de vínculos entre marcas e consumidores. Alceu, Rio de Janeiro, v. 15, p. 157-170, 2014.

TURNER, Victor. O processo ritual: estrutura e antiestrutura. Petrópolis: Vozes, 2013. (Coleção Antropologia).

VAN GENNEP, Arnold. Los ritos de paso. Madrid: Alianza Editorial, 2008.

WICKER, Jennifer. Advertising fictions in literature, advertisement and social reading: social foundations of aesthetic forms. New York: Columbia University Press, 1988. 


\section{CLOTILDE PEREZ}

cloperez@terra.com.br

Professora titular de Publicidade e Semiótica da ECA/USP. Doutora em Comunicação e Semiótica pela PUC/SP. Professora da ECA/USP na graduação em Publicidade e no Programa de Pós-Graduação em Ciências da Comunicação da USP. Líder do GESC 3 - Grupo de Estudos Semióticos em Comunicação, Cultura e Consumo. Fundadora da Casa Semio.

\section{VICTOR AQUINO}

vic@usp.br

Professor titular de Estética Publicitária da ECA/USP, na graduação em Publicidade e no Programa de Pós-graduação em Ciências da Comunicação. Líder do CEDE - Coletivo de Estudos de Estética. Editor da revista Estética. 